\title{
FINANCIAMENTO DO ENSINO MÉDIO NO BRASIL: UMA ABORDAGEM INICIAL
}

FUNDING SECONDARY EDUCATION IN BRAZIL: A FIRST APPROACH

José Marcelino de Rezende Pinto ${ }^{1}$

Resumo Há ainda, no país, uma grande carência de estudos que buscam analisar o financiamento do Ensino Médio, apesar de este ter sido o nível de ensino em que as matrículas mais cresceram no Brasil nos últimos 15 anos (232\%), tendo este crescimento ocorrido, basicamente, no setor público, com forte impacto nos gastos educacionais. Neste artigo, portanto, pretendese oferecer um panorama geral sobre o tema. Inicialmente, são apresentados e analisados os indicadores de gasto por aluno da rede pública, comparando-se as diferenças entre dependências administrativas e regiões do país, a partir de dados do INEP e do IBGE. Em seguida, são indicados os principais resultados de uma pesquisa de custo-aluno feita pela MEC. Por fim, são avaliados os recursos financeiros necessários para assegurar uma melhoria no padrão de qualidade do ensino oferecido, tendo em vista as metas quantitativas e qualitativas estabelecidas pelo Plano Nacional de Educação (PNE).

Palavras-chave ensino médio; financiamento do ensino médio; custo-aluno no ensino médio; Plano Nacional de Educação; Custo-aluno-qualidade.
Abstract Despite the fact that in Brazil, in the last 15 years, secondary education is the educational level with the highest relative increase in student numbers, $(232 \%)$ there is still an almost total lack of studies attempting to analyse governmental funding for this educational level. This is particularly surprising when one considers that the highest percentage of growth occurred in the public sector, with a huge impact on government's expenditure on education. In this article, therefore, we intend to offer an overview of the subject. Initially, with the help of INEP's and IBGE's figures, we present and analyse the indicators of expenditure per student in the State schools, comparing the differences between the country's administrative divisions and various regions. Next, we present the main findings of a cost-per-student survey done by the Brazilian Ministry of Education (MEC). Finally, we estimate the financial resources that would be necessary to guarantee a higher standard of teaching in accordance with the quantitative and qualitative aims established by the National Education Plan (PNE).

Key words secondary education; financing secondary education; cost per student in the secondary schools; cost per student/quality of education; National Education Plan. 


\section{Introdução}

O Brasil vive uma revolução silenciosa no Ensino Médio; de 1988, quando a Constituição Federal estabeleceu como um dos deveres do Estado a progressiva universalização deste nível de ensino, até 2002, suas matrículas cresceram $232 \%$, ante um crescimento de $82 \%$ no Ensino Superior, 36,5\% no Ensino Fundamental e 59\% na Pré-escola. Se analisarmos a taxa de atendimento bruta, que compara as matrículas do Ensino Médio com a população de 15 a 17 anos (faixa etária ideal para este nível de ensino), chegamos a 77\%, em 2000. Em 1991, este índice era de apenas 41 \%, o que mostra os grandes desafios que se colocam para os poderes públicos para assegurar o atendimento de uma demanda que só tende a crescer nos próximos anos, garantindo-se, ao mesmo tempo, uma melhoria na qualidade do ensino oferecido que, hoje em dia, encontra-se muito aquém daquela que o país necessita para oferecer uma boa formação a seus jovens. Este desafio fica ainda maior quando constatamos que a criação do Fundo de Manutenção e Desenvolvimento do Ensino Fundamental e de Valorização do Magistério (FUNDEF) atuou como mecanismo inibidor no financiamento do Ensino Médio, aliado ao fato que, hoje, ele é mantido quase que exclusivamente pelos estados.

Se olharmos para a nossa história, veremos que, durante cerca de 400 anos, o nível de ensino correspondente ao que hoje chamamos de Ensino Médio, viveu sob controle do setor privado. No início eram os colégios dos jesuítas, depois vieram as outras ordens religiosas, ocupando o espaço liberado com a expulsão destes em 1759. Estes estabelecimentos funcionavam como centros de formação de quadros religiosos (seminários), mas também como cursos preparatórios para os filhos da elite local que desejavam continuar seus estudos em Portugal.

Um primeiro arremedo de política pública para o setor veio com a introdução das aulas régias no fim do século XVIII. Entretanto, estas não se constituíam em um sistema orgânico de formação, já que se organizavam em aulas avulsas (Latim, Grego, Retórica, Filosofia, entre outras), com professores mal preparados, indicados mais por critérios políticos que por competência, vitalícios no cargo (que muitas vezes sublocam o direito de lecionar) e mal remunerados, visto que os recursos para manter o sistema advinham do 'subsídio literário' (um tributo que incidia sobre a venda de carne nos açougues e de aguardente).

Com a promulgação do Ato Adicional de 1834, o Ensino Secundário, juntamente com o Primário, passaram à responsabilidade das províncias, ficando o governo central responsável apenas pela educação superior e pelo ensino básico a ser oferecido no município da Corte. O máximo esforço a que o governo imperial chegou foi a criação, em 1838, do Colégio Pedro II, no Rio de Janeiro, organizado em sistema seriado com o objetivo de servir 
de modelo para os demais estabelecimentos. Isto pouco aconteceu porque somente os alunos que cursassem o Pedro II estavam isentos dos exames parcelados (realizados por disciplina) para ingresso no ensino superior. A legislação que instituiu os exames parcelados só foi extinta em 1930. Este sistema deu ao nosso ensino secundário um caráter predominantemente propedêutico e de desarticulação entre as disciplinas, que predomina até hoje.

Com a entrada no século $\mathrm{XX}$, os antigos seminários foram dando lugar aos grandes colégios, também confessionais, onde pontuavam as Congregações Maristas, os irmãos e irmãs Beneditinos, os Colégios do Sion, os Jesuítas (mais uma vez), e tantos outros que marcaram, muitas vezes fisicamente, boa parte da memória (e da pele) de nossa elite dirigente. Não é preciso dizer que todos eram pagos, embora também geralmente possuíssem mecanismos como bolsas de estudo para alunos pobres, forma pela qual buscavam sugerir um caráter filantrópico e escapar à tributação, como, aliás, ocorre até hoje (Pinto, 2002).

Com a introdução, na Constituição Federal de 1934, do princípio da vinculação para a educação de um porcentual mínimo da receita de impostos, princípio este que foi revogado na Constituição Federal de 1937 e retomado naquela de 1946 (Brasil, 1986), e com o grande crescimento econômico que marca o país nas décadas de 1940 e 1950, vemos surgir os grandes Ginásios do Estado, estabelecimentos construídos com projeto arquitetônico adequado, bem equipados com laboratórios, bibliotecas, auditórios e outros recursos didáticos, muitos dos quais ainda sobrevivem, deixando à vista o contraste com os padrões atuais de atendimento.

Nesta época, surgem também os primeiros cursos superiores destinados à formação de professores para a escola secundária. Vive-se o período de ouro da escola pública, contudo, é bom alertar que esta, embora se tratasse de uma escola que oferecia boas condições de ensino e de trabalho, possuía um caráter extremamente elitista e seletivo, tanto pela forma de ingresso (geralmente por meio de exames) quanto de progressão. Além disso, era uma escola diurna e, em muitos casos, de tempo integral, excluindo, portanto, o aluno trabalhador. Por fim, há sempre que ressaltar que a maior parte das matrículas continuava em mãos do setor privado.

Uma outra observação importante é que, nesse período, o ensino obrigatório correspondia a apenas quatro anos, compondo o antigo 'primário'. As atuais $5 \underline{a}$ a $8 \underline{a}$ séries do Ensino Fundamental compunham o 'ginásio', que correspondia ao primeiro ciclo da escola secundária, a qual ainda possuía um segundo ciclo de três anos de duração (que podia ser o 'clássico' ou o 'científico'). Portanto, quando estamos falando em domínio privado no Ensino Médio, referimo-nos a um nível de ensino de sete anos de duração, que se iniciava ao fim do exame de admissão, prova ao final da escola primária a 
que eram submetidos os poucos que haviam conseguido concluí-la e passaporte obrigatório aos que pretendiam continuar seus estudos. Paralelamente, havia também uma rede de ensino profissionalizante que, como dizia explicitamente a Carta de 1937 (Brasil, 1986), destinava-se "às classes menos favorecidas".

Esta organização só foi modificada em 1971, com a Lei no 5.692 (Brasil 1971), que acoplou o primário ao ginásio, criando o Ensino de lo Grau, hoje Ensino Fundamental, obrigatório e com oito anos de duração, e o Ensino de 20 Grau, hoje Ensino Médio, com três anos de extensão. Esta alteração na organização do ensino secundário trará mudanças profundas nos anos seguintes. De um lado, com o aumento da obrigatoriedade para oito anos, o Estado se vê compelido a ampliar a oferta de vagas e isto exatamente em plena ditadura militar, um período em que os gastos com educação atingiam seus patamares mais baixos, decorrentes, entre outras coisas, da retirada da vinculação constitucional de recursos para educação na Constituição de 1967 (Brasil, 1967). O resultado foi uma expansão a custo zero, multiplicando-se os turnos escolares e achatando-se os salários, com prédios precários, professores mal preparados e desmotivados, lançando as raízes de nossa atual escola de massas e para as massas, em oposição às escolas da elite.

Neste último segmento, mudanças radicais também foram observadas, com as antigas escolas confessionais de formação mais centradas nas humanidades, dando lugar às modernas empresas de ensino, guiadas pelas leis de mercado e cujo principal objetivo é preparar seus alunos para ingresso na educação superior.

\section{Situação atual do financiamento}

Estes fatos nortearam o financiamento do Ensino Médio até a promulgação da Constituição Federal de 1988, que sinalizou, de forma clara, a mudança para um outro padrão, estabelecendo o acesso a este nível de ensino como um direito do cidadão e como um dever do Estado, mesmo que de cumprimento não imediato como consta em seu art. 208 (Brasil, 2003). A Lei de Diretrizes e Bases da Educação (Brasil, 1996) reforça este princípio, além de estabelecer a oferta deste nível de ensino como de responsabilidade prioritária dos governos estaduais cabendo, contudo, à União, a função de assegurar a equalização das oportunidades educacionais entre as diferentes regiões do país e de garantir um padrão mínimo de qualidade mediante assistência técnica e financeira, dever poucas vezes cumprido (CF, art. 211 e LDB, art. 10).

O gráfico 1 mostra de forma evidente o impacto positivo que este princípio constitucional teve na expansão da oferta do Ensino Médio. A partir dele, verifica-se a grande expansão da rede pública na década de 1990 e o 
congelamento das matrículas na rede privada. Assim, essa rede privada que, em 1970, respondia por $45 \%$ das matrículas, cai para um índice de $13 \%$, em 2002. Cabe ainda dizer que, segundo os dados do INEP (2003), dos $8,7 \mathrm{mi}-$ lhões de alunos matriculados no Ensino Médio em 2002, a rede estadual respondia por $84 \%$ das matrículas, a rede municipal por $2 \%$, e a rede federal por ínfimo $1 \%$ do total.

\section{Gráfico 1}

Evolução das matrículas no Ensino Médio por dependência — 1970-2002

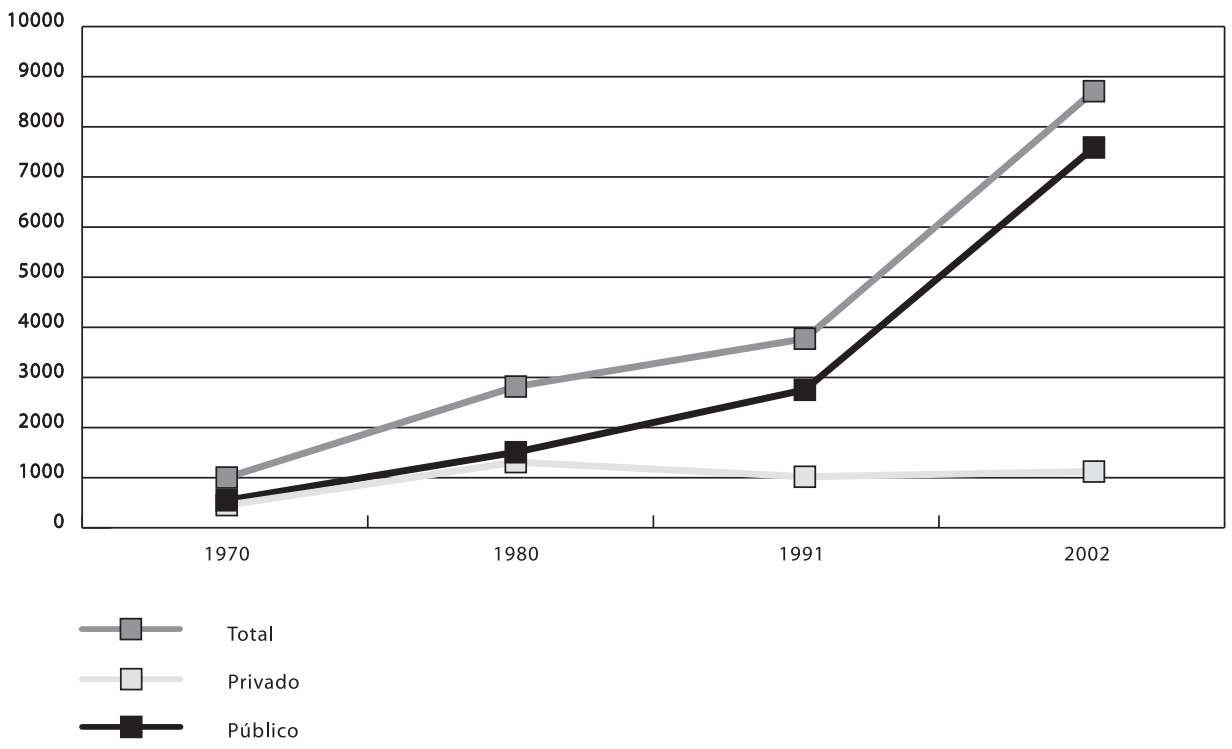

Fonte: MEC/INEP

Analisemos, a seguir, como os gastos por aluno evoluíram. No caso deste indicador, os dados disponíveis pelo INEP são bem mais recentes e a metodologia de mensuração ainda se encontra em fase de consolidação. Isso ocorre devido ao fato que boa parte dos balanços orçamentários não trazem um detalhamento claramente definido das despesas com educação discriminadas pelos diferentes níveis de ensino e, como veremos mais adiante, a introdução do Fundef ainda ampliou estes problemas. Portanto, os dados apresentados nos gráficos 2 e 3 devem ser vistos como uma primeira aproximação para os valores por aluno efetivamente gastos.

De acordo com o gráfico 2, o que se constata, em primeiro lugar, é que não existem grandes diferenças nos valores de gasto por aluno/ano entre o 
Ensino Fundamental e o Ensino Médio. Isto se deve ao fato que, no que se refere à infra-estrutura e aos equipamentos, não há grandes diferenças entre os níveis de ensino, pois ambos são igualmente carentes dos mesmos, além de ser muito comum uma mesma escola abrigar turmas de $5 \underline{a}$ a $8 \underline{a}$ séries e de Ensino Médio.

Os salários dos docentes, elemento de maior peso nos gastos, assumem maiores valores para os que ensinam na escola secundária, efeito que acaba sendo neutralizado pelo maior número de alunos por turma. Um dado, contudo, que merece atenção é que, pelos dados do gráfico 2, em 1999, pela primeira vez no período analisado, os gastos por aluno-ano no Ensino Médio ficaram abaixo daqueles do Ensino Fundamental. Este fato não parece ser um caso isolado para o ano de 1999 e tem sido observado em uma série de estudos e pesquisas mais recentes que buscam analisar o impacto do Fundef nos sistemas estaduais (Souza Júnior, 2003; Gouveia et al., 2003, entre outros).

Boa parte destes estudos tem indicado uma queda incompatível nos valores de gastos por aluno-ano no Ensino Médio enquanto as matrículas continuam a crescer em ritmo acelerado. Possível explicação para este fato parece estar na forma com que os sistemas estaduais vêm contabilizando os gastos com os professores que lecionam neste nível de ensino. Como boa parte deles também ministra aulas no Ensino Fundamental, em especial nas turmas de $5 \underline{a}$ a $8 \underline{a}$ séries, seus salários são contabilizados parcial, ou integralmente neste nível de ensino, para efeito de prestação de contas ao Fundef, numa clara burla, de difícil detecção, à legislação deste Fundo. Ao que parece, este tem sido um mecanismo utilizado por alguns governos estaduais para garantir a expansão das matrículas no Ensino Médio. Um segundo mecanismo consiste no adensamento das turmas, de tal forma que a relação alunos/turma saltou de 35, em 1991, para 40, em 2000 (INEP, 2003). Por fim, os dados do gráfico 2 apontam para uma estabilidade, em termos reais, nos gastos/aluno no período de 1995-98, com uma queda no último ano da série, que corresponde exatamente ao período de implantação do Fundef.

Uma forma que permite comparar as despesas educacionais de um país com outros é transformar o valor gasto por aluno em um porcentual do PIB per capita, mesmo que esta metodologia possa sofrer críticas, já que o PIB per capita dos países mais ricos é dezenas de vezes maior que o correspondente dos países pobres. De qualquer forma, não deixa de ser uma maneira de medir o comprometimento educacional de um país comparado com suas próprias potencialidades e riqueza. O resultado desta conta para o Brasil é mostrado no gráfico 3, que indica uma queda crescente neste índice, saindo de $14 \%$ do PIB per capita, em 1994, para 11,1\%, em 1999. A média no período foi de um gasto por aluno-ano no Ensino Médio como equivalente a $12,9 \%$ do PIB per capita. 
Gráfico 2

Evolução dos gastos por aluno — 1994-1999 (em R\$ de 1999)

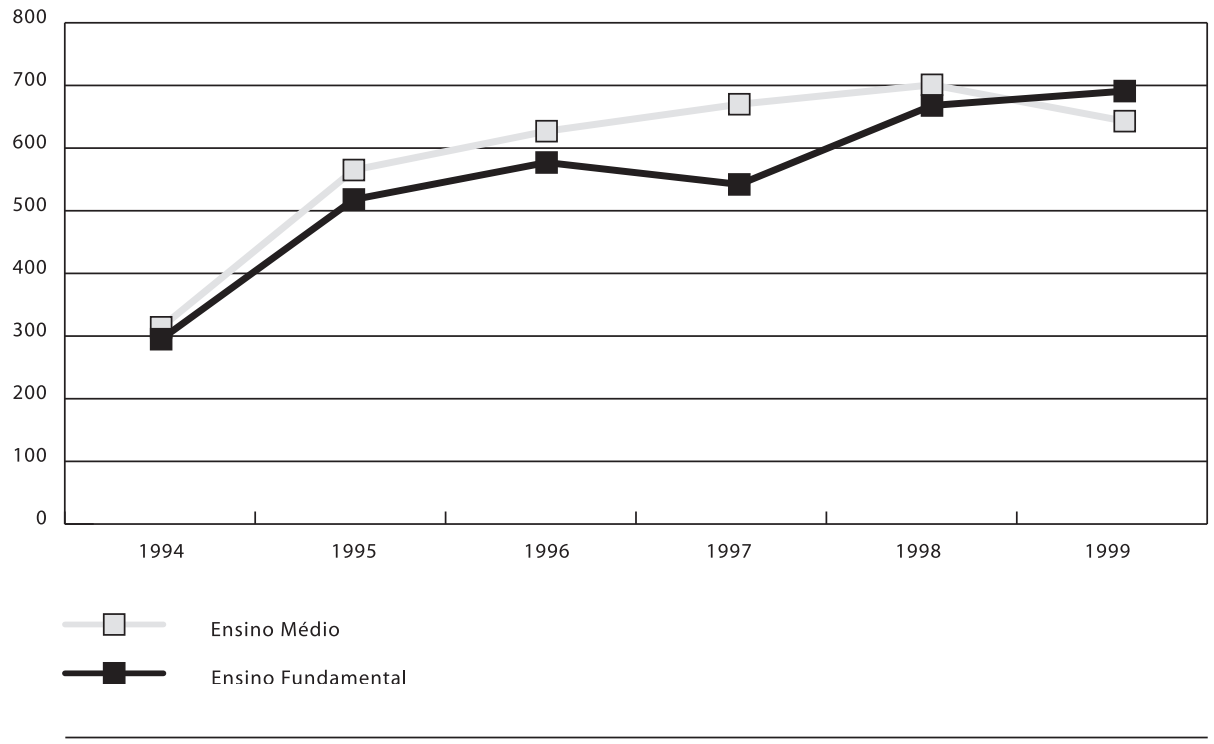

Fonte: IPEA/DISOC, MEC/INEP

Nota: O deflator utilizado foi o IGP-DI.

\section{Gráfico 3}

Gasto por aluno-ano no ensino médio como percentual do PIB per capita - 1994-1999

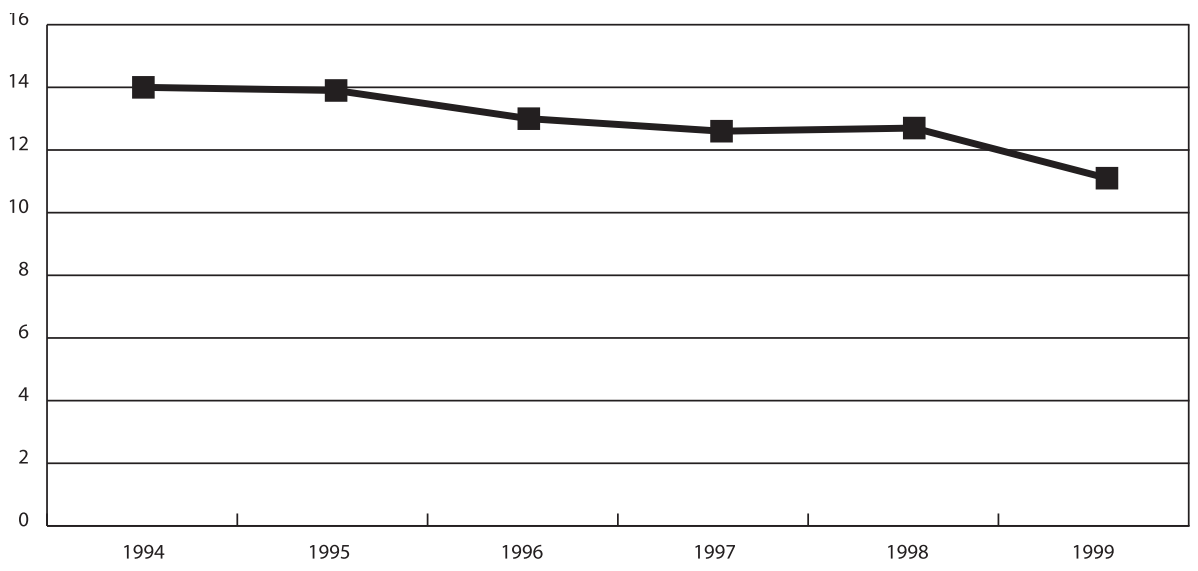

\% do PIB per capita 
Trata-se de um valor bem baixo quando comparado, por exemplo, com a média dos países da Organização para a Cooperação Econômica e para o Desenvolvimento (OECD), que foi de $28 \%$ em 1999. Nunca é demais lembrar que, como o PIB per capita desses países é muito maior, este valor representa muito mais não só em termos relativos, mas também em termos absolutos. No caso, o gasto médio foi de US\$ 5919, em dólares ajustados ao poder de paridade de compra de bens entre os diferentes países. Em padrão equivalente, nosso gasto por aluno-ano foi de US\$ 794. Mesmo entre os países mais pobres e que fazem parte da WEI (World Education Indicators), esta média foi de $22 \%$ do PIB per capita em 1999 (WEI, 2003).

Vejamos agora como os valores de gastos por aluno na rede estadual, que responde por mais de $96 \%$ das matrículas na rede pública, variam entre os estados da federação. Os resultados são mostrados no gráfico 4 e indicam uma grande variação. Neste gráfico, pode-se verificar que a razão entre o maior valor - o do DF, com R\$1251/aluno-ano - e o menor - o de Alagoas, com R\$377/aluno-ano - é de 3,3 vezes. Constata-se, ainda, que na maioria das redes estaduais (18) o valor per capita situa-se na faixa entre R\$ 400 e $\mathrm{R} \$ 700$, para uma média nacional de $\mathrm{R} \$ 609$.

\section{Gráfico 4}

Gasto por aluno no ensino médio na rede estadual - 1999

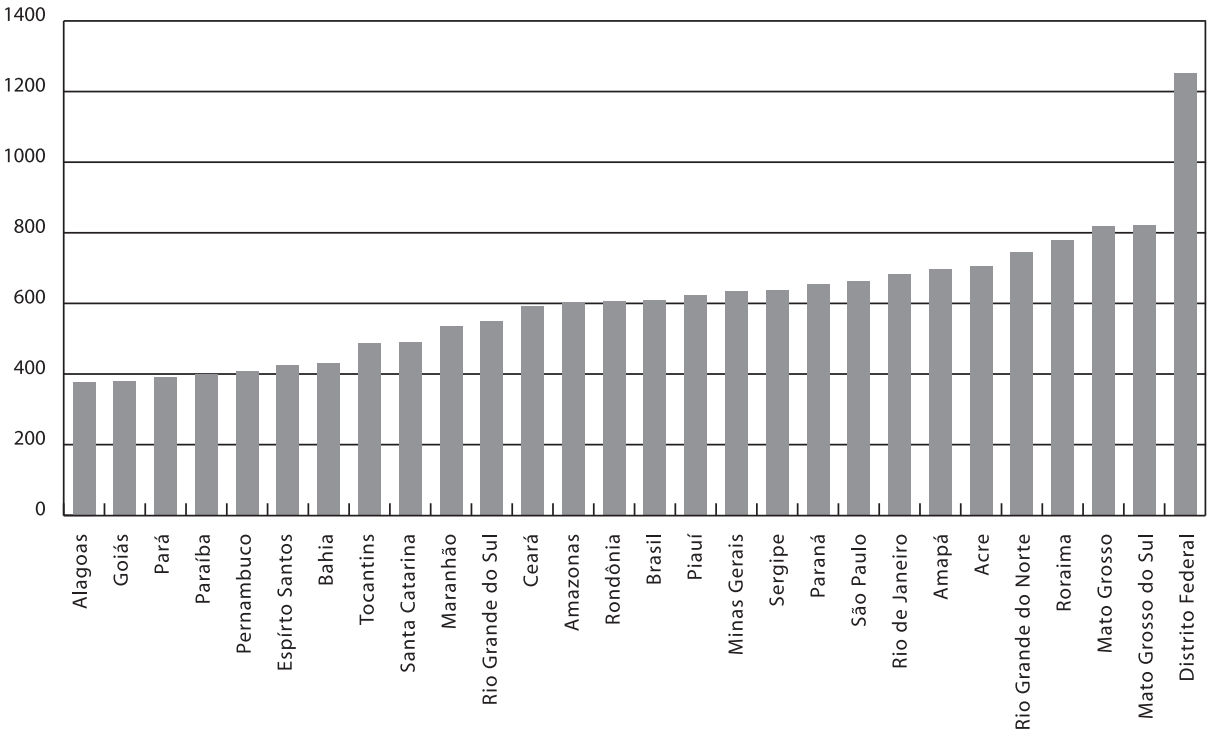


Analisemos agora as diferenças no valor per capita entre a rede estadual e a federal nas diferentes regiões do país, já que não temos disponíveis os dados municipais. Os dados apresentados no gráfico 5 são eloqüentes, evidenciando aquilo que qualquer observador atento de nosso sistema de ensino já sabe. Há no Brasil dois padrões de Ensino Médio público: de um lado, as redes estaduais, que atendem à maioria dos estudantes, com valores, em 1999, de cerca de R \$ 50/aluno-mês; de outro lado, uma rede federal composta basicamente por escolas técnicas e pelo Colégio Pedro II, com gastos de cerca de $\mathrm{R} \$ 180 /$ aluno-mês e que oferece um ensino claramente diferenciado. Apesar dessa diferença, cabe comentar que o valor da rede federal ainda está bem abaixo de boa parte das escolas privadas consideradas de boa qualidade.

\section{Gráfico 5}

Gasto aluno no ensino médio por dependência e região- 1999 (em R\$)

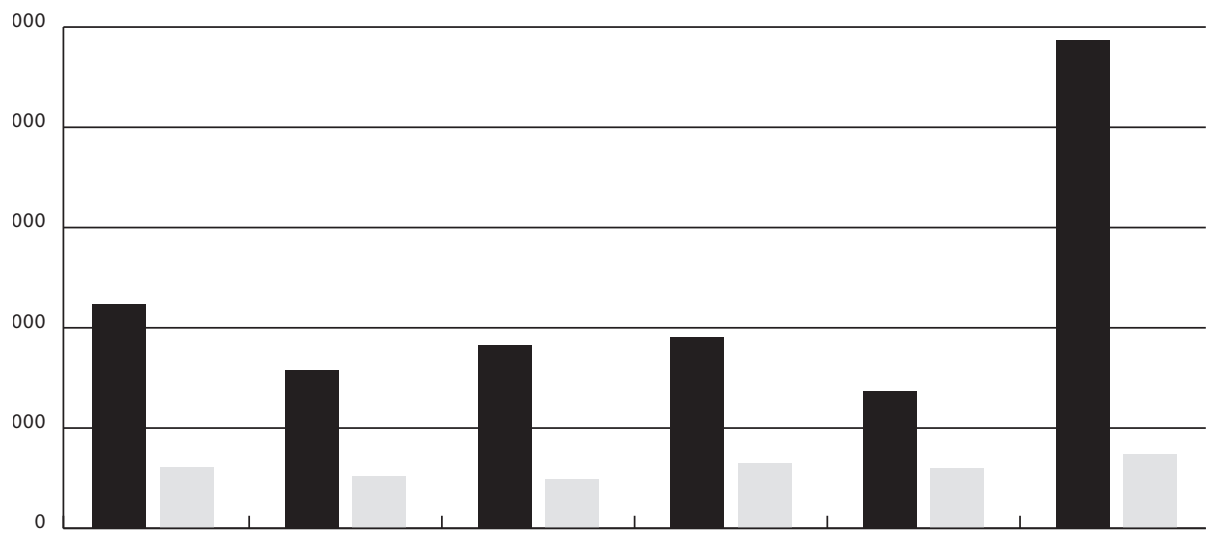

Fonte: MEC/INEP

Discutindo ainda as diferenças entre as diversas redes, a tabela 1 apresenta um conjunto de indicadores que mostram claramente que as escolas federais, mais do que as privadas, são aquelas que apresentam um melhor conjunto de indicadores referentes às condições de oferta do ensino e às condições de trabalho para os docentes. 
Tabela 1

\begin{tabular}{|c|c|c|c|c|}
\hline \multirow[t]{2}{*}{ Indicador } & \multicolumn{4}{|c|}{ Dependência Administrativa } \\
\hline & Federal & Estadual & Municipal & Particular \\
\hline Alunos por turma & 31 & 40 & 37 & 32 \\
\hline Horas-aula por dia & 5,1 & 4,2 & 4,0 & 4,9 \\
\hline Professores c/nível superior (\%) & 97 & 89 & 64 & 89 \\
\hline Escolas com Biblioteca (\%) & 98 & 80 & 56 & 91 \\
\hline Escolas com Lab. de Inform. (\%) & 94 & 38 & 16 & 75 \\
\hline Salários (1997) & 1.548 & 639 & 505 & 838 \\
\hline
\end{tabular}

Fonte: MEC/INEP

Tabela 2

\begin{tabular}{|c|c|c|c|c|c|c|}
\hline Atividade Profissional & Brasil(R\$) & Norte(R\$) & $\mathrm{Ne}(\mathrm{R} \$)$ & $\mathrm{Se}(\mathrm{R} \$)$ & Sul(R\$) & $\mathrm{CO}(\mathrm{R} \$)$ \\
\hline \multicolumn{7}{|l|}{ Professor } \\
\hline Ed.Infantil & 423 & 389 & 233 & 522 & 436 & 750 \\
\hline $1^{\text {a }}$ a $4^{\text {a }}$ séries & 462 & 443 & 293 & 599 & 553 & 567 \\
\hline $5^{\mathrm{a}}$ a $8^{\mathrm{a}}$ séries & 600 & 601 & 373 & 793 & 634 & 594 \\
\hline Ensino Médio & 866 & 826 & 628 & 979 & 804 & 872 \\
\hline Ed.Superior & 2.565 & 1.800 & 2.252 & 3.087 & 2.123 & 2.190 \\
\hline Advogado & 2.497 & 3.894 & 2.245 & 2.431 & 2.597 & 2.768 \\
\hline Médico & 2.973 & 4.430 & 2.577 & 2.802 & 3.260 & 4.111 \\
\hline Policial Civil & 1.510 & 1.344 & 1.320 & 1.458 & 1.488 & 2.087 \\
\hline Delegado & 2.661 & 2.754 & 1.347 & 2.651 & 3.714 & 5.970 \\
\hline Oficial das F. Armadas & 2.092 & 2.129 & 1.674 & 2.251 & 1.950 & 2.321 \\
\hline
\end{tabular}

Fonte: IBGE (Pnad-2001)

Nota: dados trabalhados por MEC/INEP (2003a) e adaptados pelo autor.

A situação dos salários, que, como dissemos, é um integrante de custos fundamental nas discussões sobre financiamento e qualidade, tanto por seu peso nos custos totais como por seu papel de elemento decisivo para atrair profissionais qualificados para a docência, exige um maior detalhamento. A tabela 2, feita com base em dados do IBGE, mostra a situação dos salários dos professores em comparação com os de outras profissões. Por ela, observa-se que, se de forma geral os professores que atuam no Ensino Médio recebem uma remuneração acima daquela de seus colegas que atuam no Ensino Fundamental e na Educação Infantil, quando comparados com profissionais de nível de formação equivalente, encontram-se num patamar bem inferior, recebendo menos da metade da remuneração. Mesmo uma profissão do setor público que não exige diploma de nível superior, como é o caso do Policial Civil, remunera em cerca de $74 \%$ acima do que ganha um professor 
daquele nível de ensino. No que se refere à comparação entre as diferentes regiões do país, ao contrário do que ocorre com os professores que atuam em outros níveis de ensino, não se observam grandes discrepâncias. Cabe ressaltar que o valor ali incluído refere-se àquele que o profissional declara ao pesquisador do IBGE.

Um outro estudo interessante que pode subsidiar as análises sobre o financiamento do Ensino Médio, intitulado O custo aluno no ensino médio (MEC, 2002), foi feito pela Fundação Fipe a partir de uma solicitação do MEC. O trabalho foi realizado em 71 escolas de sete estados (BA, MG, PA, $\mathrm{PR}, \mathrm{PE}, \mathrm{SP}$ e GO), consideradas como típicas de seus sistemas de ensino. A pesquisa levantou os custos diretos das escolas, assim como os custos indiretos referentes às estruturas de apoio administrativo e pedagógico das respectivas Secretarias de Educação. As tabelas 3 e 4 apresentam os principais resultados do estudo que, para os salários, usou dados de 2001 e, para os demais itens, dados de 2000.

Da análise dos dados das tabelas 3 e 4 gostaríamos de destacar, em primeiro lugar, o peso dos gastos indiretos em alguns sistemas, o que parece indicar uma utilização inadequada dos recursos. Um segundo ponto referese ao peso, relativamente elevado, dos gastos com pessoal de direção e, ain$\mathrm{da}$, dos gastos, em geral muito pequenos, com material de consumo e material permanente. As despesas com pessoal em sala de aula responderam, na maioria dos estados, por cerca de $60 \%$ dos custos totais.

Tabela 3

\begin{tabular}{|c|c|c|c|c|c|}
\hline Estado* & A & B & $C$ & $\mathrm{~A} / \mathrm{C}$ & $\mathrm{B} / \mathrm{C}$ \\
\hline & $\begin{array}{c}\text { Custo direto } \\
\text { (R\$) }\end{array}$ & $\begin{array}{c}\text { Custo Indireto } \\
\text { (R\$) }\end{array}$ & $\begin{array}{l}\text { Custo Total } \\
\text { (R\$) }\end{array}$ & $(\%)$ & $(\%)$ \\
\hline E1 & 301 & 168 & 469 & 64 & 36 \\
\hline E2 & 329 & 36 & 365 & 90 & 10 \\
\hline E3 & 503 & 117 & 620 & 81 & 19 \\
\hline E4 & 505 & 50 & 555 & 91 & 9 \\
\hline E5 & 559 & 70 & 629 & 89 & 11 \\
\hline E6 & 593 & 110 & 703 & 84 & 16 \\
\hline E7 & 577 & 173 & 750 & 77 & 23 \\
\hline
\end{tabular}

Fonte: MEC. 2002. O custo aluno no ensino médio. Brasília, MEC/SEMTEC.

*Os Estados não são identificados no estudo do MEC. 


\begin{tabular}{lccccccc}
\hline Participação dos principais componentes de custo direto aluno-ano no Ensino Médio - 2000-2001 \\
\hline Estados* & E1 & E2 & E3 & E4 & E5 & E6 & E7 \\
\hline Salários (\%) & 78 & 90 & 85 & 77 & 89 & $\mathbf{8 2}$ & $\mathbf{8 8}$ \\
$\quad$ Pessoal com atividade em aula & 41 & 58 & 57 & 54 & 58 & 46 & 58 \\
$\quad$ Direção & 9 & 9 & 12 & 8 & 5 & 14 & 14 \\
Apoio Administrativo & 5 & 6 & 5 & 7 & 7 & 8 & 6 \\
Apoio ao Ensino & 7 & 8 & 1 & 1 & 1 & 3 & 3 \\
Manutenção e Limpeza & 14 & 4 & 7 & 5 & 9 & 5 & 4 \\
$\quad$ Outros salários** & 2 & 5 & 3 & 2 & 9 & 6 & 3 \\
Contas de água, luz, fone e IPTU (\%) & 4 & 3 & 2 & 4 & 3 & 6 & 2 \\
Material de consumo (\%) & 10 & 1 & 3 & 2 & 1 & 2 & 2 \\
Material permanente (\%) & 0,4 & 0,1 & 0,7 & 0,5 & 0,3 & 2,0 & 0,2 \\
Depreciação (\%) & 7 & 5 & 6 & 5 & 5 & 8 & 6 \\
Gastos não realizados por falta & 1 & 1 & 3 & 11 & 1 & 0 & 1 \\
de recursos financeiros (\%) & & & & & &
\end{tabular}

Fonte: MEC. 2002.

*Os Estados não são identificados no estudo do MEC.

** Inclui pessoal afastado e outras despesas com pessoal.

Nota: a soma das parcelas pode não ser igual a $100 \%$ em virtude dos arredondamentos.

\section{Em busca de uma escola de qualidade para todos}

Conforme já afirmamos, o Brasil possui dois grandes desafios no que se refere ao Ensino Médio. O primeiro é ampliar a oferta com vistas a assegurar sua universalização, como apontam a Constituição Federal, a Lei de Diretrizes e Bases da Educação (Lei 9394/96) e o Plano Nacional de Educação (Lei 10.172/2001). O segundo consiste em assegurar uma melhoria progressiva no padrão de qualidade do ensino oferecido. Hoje, na rede majoritária, que é a estadual, o Ensino Médio convive com as sobras do Ensino Fundamental. Como conseqüência desta realidade, a metade dos alunos está matriculada no período noturno; os eventuais laboratórios existentes não são utilizados; bibliotecas, quando existem, não passam de uma sala de leitura ou depósito de livros, sem um profissional habilitado para seu manejo. As exceções a este padrão são a rede federal e, em menor grau, a rede privada.

Esta última, no entanto, tendo em vista a demanda de suas clientelas e a lógica que preside a sua administração, oferece um ensino bastante deficiente, totalmente direcionado à preparação para o vestibular e longe do que postula a LDB, em seu art. 35, como finalidades do Ensino Médio. Segundo a lei, essas finalidades devem contemplar, além da preparação para o prosseguimento dos estudos, o preparo básico para o trabalho e o aperfeiçoamento do educando como pessoa, estimulando sua autonomia intelectual e pensamento crítico, garantindo a compreensão dos fundamentos científi- 
co-tecnológicos que subjazem aos processos produtivos, e relacionando teoria e prática. Por esta descrição, pode-se verificar que a rede federal talvez seja a única que chegue mais próximo dos objetivos legais. Contudo, com o valor do gasto por aluno desta rede, que corresponde a cerca de $38 \%$ de nosso PIB per capita, torna-se difícil pensar em sua generalização.

Como estímulo ao debate, construímos na tabela 5 uma escola hipotética, onde sugerimos parâmetros de qualidade de oferta bem superiores aos atualmente praticados pela rede estadual, mas que chega a valores por aluno medidos em termos de percentual do PIB per capita compatíveis com os padrões internacionais. Ela foi concebida com 900 alunos, com médias de 30 alunos por turma, cinco horas diárias de aulas ( 25 horas por semana) e professores com jornada de 40 horas ( 30 horas com os alunos e 10 em preparação e planejamento na própria escola). Estes professores contariam com auxiliares de ensino (estagiários remunerados). A instituição seria dotada de bibliotecas e laboratórios, e teria recursos para a aquisição de materiais didáticos, renovação e manutenção de equipamentos. Estariam previstos, ainda, recursos para a formação continuada de seus profissionais.

Os dados apresentados na tabela 5 mostram que é possível fazer uma escola radicalmente diferente do padrão dominante de hoje, mas dentro de um patamar aceitável de gastos por aluno, ou seja, cerca de R $\$ 1.700(22,3 \%$ do PIB per capita), que é inferior ao abatimento das despesas escolares no Imposto de Renda para quem estuda ou tem dependente na rede privada (o referente a $\mathrm{R} \$ 1.998,00)$.

Desenhada nossa "escola de qualidade", precisamos analisar qual seria o impacto de sua generalização progressiva na rede pública, considerando ainda o aumento de matrículas, previsto pelas metas estabelecidas pelo Plano Nacional de Educação. Os dados apresentados na tabela 6 indicam que, para atingirmos no prazo de oito anos, a contar de agora, as metas de expansão de quantidade e qualidade definidas pelo PNE, seria necessário sair do atual patamar de gastos com o Ensino Médio, da ordem de 0,5\% do PIB, para cerca de $1,45 \%$. Contudo, com a regularização do fluxo, que deve levar a uma queda nas matrículas, este porcentual deve chegar a um patamar de $1 \%$ do PIB, um índice bem próximo daquele verificado em outros países (WEI, 2003). 
Tabela 5

\begin{tabular}{|c|c|c|c|c|c|}
\hline \multicolumn{6}{|l|}{ I - Custos em sala de aula } \\
\hline & Unidade & $\begin{array}{l}\text { Unitário } \\
\text { (R\$) }\end{array}$ & $\begin{array}{l}\text { Total/ano } \\
\quad(\mathrm{R} \$)\end{array}$ & $\begin{array}{l}\text { Aluno/ano } \\
\text { (R\$) }\end{array}$ & $\%$ do total \\
\hline Professores & 25 & $2.000,00$ & $666.500,00$ & 740,56 & 43,8 \\
\hline Auxiliar (estagiário) & 30 & 300,00 & $108.000,00$ & 120,00 & 7,1 \\
\hline Material didático & 900 & 100,00 & $90.000,00$ & 100,00 & 5,9 \\
\hline Equipamento (renovação) & & & $40.000,00$ & 44,44 & 2,6 \\
\hline Subtotal & & & $904.500,00$ & $1.005,00$ & 59,4 \\
\hline
\end{tabular}

II - Custos no âmbito da escola

\begin{tabular}{|c|c|c|c|c|c|}
\hline \multicolumn{6}{|l|}{ Administração geral } \\
\hline Direção & 2 & $2.000,00$ & $53.320,00$ & 59,24 & 3,5 \\
\hline Secretaria & 2 & 800,00 & $21.328,00$ & 23,70 & 1,4 \\
\hline Vigilância & 3 & 400,00 & $15.996,00$ & 17,77 & 1,1 \\
\hline Limpeza & 4 & 400,00 & $21.328,00$ & 23,70 & 1,4 \\
\hline Subtotal & & & $111.972,00$ & 124,41 & 7,4 \\
\hline \multicolumn{6}{|l|}{ Suporte Pedagógico } \\
\hline Coord.pedagógico & 3,0 & $1.600,00$ & $63.984,00$ & 71,09 & 4,2 \\
\hline Supervisor de alunos & 2 & 240,00 & $6.398,00$ & 7,11 & 0,4 \\
\hline Bibliotecário & 2 & $1.500,00$ & $39.990,00$ & 44,43 & 2,6 \\
\hline Subtotal & & & $110.372,00$ & 122,64 & 7,2 \\
\hline \multicolumn{6}{|l|}{ III - Operação e manutenção } \\
\hline Água/luz/fone & 12 meses & $2.500,00$ & $30.000,00$ & 33,33 & 2,0 \\
\hline Conservação predial & 12 meses & $2.000,00$ & $24.000,00$ & 26,67 & 1,6 \\
\hline Manut. Equipamentos & 12 meses & 600,00 & $7.200,00$ & 8,00 & 0,5 \\
\hline Subtotal & & & $61.200,00$ & 68,00 & 4,0 \\
\hline \multicolumn{6}{|l|}{ IV - Encargos } \\
\hline Encargos sociais* & & & & 221,52 & 13,1 \\
\hline \multicolumn{6}{|c|}{ V - Custos na administração central } \\
\hline Formação profissional & 30 & 400,00 & $12.000,00$ & 13,33 & 0,8 \\
\hline Administração e Supervisão & & & $123.716,00$ & 137,46 & 8,1 \\
\hline Subtotal & & & $135.716,00$ & 150,80 & 8,9 \\
\hline Total Geral & & & $132.3760,00$ & $1.692,37$ & 100,00 \\
\hline
\end{tabular}

Custo total por aluno-ano (em \% do PIB per capita) 22,3\%

Fonte: o autor

* Considerados como equivalentes a $20 \%$ do gasto com pessoal. 
Recursos Necessários para Atendimento das Metas do PNE no Ensino Médio — 2003-2011

\begin{tabular}{|c|c|c|c|c|c|c|c|c|c|}
\hline & 2003 & 2004 & 2005 & 2006 & 2007 & 2008 & 2009 & 2010 & 2011 \\
\hline $\begin{array}{l}\text { Matrícula no Setor } \\
\text { Público (em mil) }\end{array}$ & 7.865 & 8.586 & 9.302 & 10.274 & 11.168 & 11.837 & 12.202 & 12.638 & 12.574 \\
\hline $\begin{array}{l}\text { Gasto/Aluno } \\
\text { estimado (em } \mathrm{R} \$ \text { ) }\end{array}$ & 880 & 1.049 & 1.164 & 1.302 & 1.455 & 1.625 & 1.815 & 2.026 & 2.173 \\
\hline $\begin{array}{l}\text { Gasto/Aluno } \\
\text { (em \% PIB Per Capita) }\end{array}$ & 11,5 & 13,43 & 14,53 & 15,71 & 17,00 & 18,39 & 19,89 & 21,52 & 22,3 \\
\hline $\begin{array}{l}\text { Recursos Financeiros } \\
\text { (R\$ milhões) }\end{array}$ & 6.921 & 9.011 & 10.832 & 13.374 & 16.247 & 19.236 & 22.147 & 25.609 & 28.520 \\
\hline $\begin{array}{l}\text { Recursos Financeiros } \\
(\% \mathrm{PIB})\end{array}$ & 0,51 & 0,64 & 0,75 & 0,88 & 1,02 & 1,16 & 1,28 & 1,41 & 1,45 \\
\hline
\end{tabular}

Fonte: MEC/INEP (2003c)

Nota: Os valores estão calculados tendo por base o ano de 2003, considerando as estimativas oficiais de crescimento do PIB, e não contêm estimativa de inflação.

\section{Considerações finais}

Este trabalho procurou apresentar, em uma primeira aproximação, uma síntese do que apontam os dados atualmente existentes sobre as condições de ensino e de financiamento do Ensino Médio no Brasil. Eles apontam que foi feito um esforço gigantesco, desde a aprovação da Constituição de 1988, com vistas a atender à demanda por mais vagas neste nível de ensino, em especial por parte dos governos estaduais; que, infelizmente, o preço de expansão foi uma deterioração da qualidade; que os valores gastos anualmente por estudante são cerca da metade daqueles praticados por países de riqueza equivalente, quando se toma por referência o PIB per capita; e que a rede federal é aquela que apresenta os melhores indicadores de qualificação de docentes, infra-estrutura, equipamentos e salários. Infelizmente, esta rede tem uma participação ínfima no total de matrículas e, portanto, pode, quando muito, servir de paradigma sobre o que seja uma escola secundária de qualidade.

Quanto à rede privada, muito embora apresente condições de ensino superiores às suas congêneres estaduais e municipais, na média das escolas ainda encontram-se graves problemas, como falta de pessoal com a qualificação mínima legalmente exigida, ausência de bibliotecas e de laboratórios de informática, e salários que estão distantes daqueles praticados pela rede federal, embora suas anuidades estejam muito acima dos gastos por alunoano do sistema público.

Por fim, foi apresentada uma escola hipotética com condições de ensino e de trabalho docente superiores ao padrão atual, com seus respectivos va- 
lores de custo. Estes indicam a necessidade de uma duplicação nos gastos per capita para atingirmos o padrão proposto. Trata-se de um desafio significativo, contudo, plenamente realizável, tendo em vista não só as potencialidades econômicas do país mas também os ganhos sociais e econômicos que adviriam desta verdadeira revolução no Ensino Médio. Ele deixaria de ser um intruso que hoje cresce nas sobras e turnos ociosos da escola de Ensino Fundamental e ganharia uma identidade própria, uma identidade que já teve no passado e que o sistema federal conseguiu preservar, apesar dos estragos causados pelo Dec. 2.208/97.

O grande desafio é como financiar esta escola secundária reconstruída em novas bases e com vocação para a universalidade. Um fato é inegável: não se trata de falta de recursos. O Brasil possui uma carga fiscal da ordem de $30 \%$ do seu PIB, que propicia um montante razoável de recursos públicos. Destes, a educação fica com cerca de $15 \%$ do total, um índice muito pequeno para o caráter estratégico que o setor possui.

Por outro lado, neste e nos últimos anos, mais de $8 \%$ do PIB foram gastos com pagamentos de juros e com os serviços das dívidas interna e externa sem que, com isso, estas tivessem seu montante reduzido. Além disso, em 2002, o setor bancário do país apresentou um lucro da ordem de R 15 bilhões, um valor que representa mais de duas vezes tudo o que se gastou com as escolas públicas secundárias do país. Percebe-se, claramente, uma inversão de prioridades. Constata-se ainda, como agravante, que a soberania dos estados nacionais (sejam eles grandes ou pequenos) frente aos grandes conglomerados financeiros é cada vez menor.

Portanto, mostra-se desafiador o horizonte para uma ampliação dos gastos com educação do país, que, conforme relatório do grupo de estudo criado pelo Ministro da Educação (Inep, 2003c), deveria ser da ordem de 8\% do PIB nos próximos 10 anos, para viabilizar a revolução educacional de que o país precisa. Porém, como o problema do Estado moderno não é a falta de recursos financeiros, mas onde eles são aplicados, não há porque desanimar nesta luta, mesmo porque, como mostra a experiência das nações ricas, fora da educação não há futuro, em particular para os jovens. 


\section{Nota}

1 Professor licenciado da Faculdade de Filosofia, Ciências e Letras de Ribeirão Preto (FFCLRP-USP), atualmente, Diretor de Tratamento e Disseminação de Informações Educacionais do INEP. Doutor em Educação pela UNICAMP. < jose.pinto@inep.gov.br>

\section{Referências bibliográficas}

BRASIL. Leis. Constituição da República Federativa do Brasil. Brasília, Senado Federal, 2003.

. Lei Federal 10.172, de 9/01/2001. Aprova o Plano Nacional de Educação (PNE) e dá outras providências. Brasília, 2001. . Lei Federal 9.394, de 20/12/1996. Lei De Diretrizes e Bases da Educação Nacional (LDB). Brasília, 1996.

_. Constituições do Brasil: 1824, 1891, 1934, 1937, 1946 e 1967 e suas alterações. Brasília, Senado Federal, 1986.

. Lei Federal 5.692, de 11/08/1971. Lei de Diretrizes e Bases da Educação Nacional. Brasília, 1971.

GOUVEIA, Andréia Barbosa et al. 2003. A implantação e os impactos do Fundef no Estado do Paraná. Relatório de Pesquisa. Curitiba: Universidade Federal do Paraná, Setor Educação, Núcleo de Política, Gestão e Financiamento. (cd-rom). MEC. 2002. O custo aluno no ensino médio. Brasília: MEC/SEMTEC.

MEC/INEP. 2003a. Estatísticas dos Professores no Brasil. Disponível em: <www. inep.gov.br>. Acesso em: 12 dez. 2003. 2003b. A Educação no Brasil na década de 90. Disponível em: <www. inep. gov.br>. Acesso em: 12 dez. 2003.

_. 2003c. Relatório do Grupo de Trabalho sobre financiamento da educação. Revista Brasileira de Estudos Pedagógicos, 82 (200/201/202):117-134.

PINTO, José Marcelino de Rezende. 2000. O financiamento da educação no Brasil no contexto das finanças públicas. Brasília, Plano Editora.

2002. O Ensino Médio. In: Organização do ensino no Brasil (Portela, R.O. e Adrião, T., orgs.), pp. 51-77, São Paulo: Xamã.

SOUZA JÚNIOR, Luiz de. 2003. Financiamento da Educação: Os impactos do Fundef na Educação Básica do Estado da Paraíba. Tese de Doutorado. São Paulo, Faculdade de Educação da USP.

WEI (World Education Indicators). 2003. Financing Education - Investments and returns. Analysis of the world education indicators. 2002 edition. Paris, França, UNESCO-UIS/OECD. 